\title{
Autonomic failure with persistent fever in cerebral gigantism
}

\author{
O. APPENZELLER AND R. D. SNYDER \\ From the Departments of Medicine (Neurology) and Pediatrics, \\ University of New Mexico Medical School, Albuquerque, New Mexico, U.S.A.
}

Fever is normally related to the activity of pyrogens. These substances do not affect blood vessels or post-ganglionic sympathetic nerves, nor do they influence the responses elicited by heating of skin receptors. Fever is most probably produced by the direct action of pyrogens on central structures concerned with temperature regulation (Cooper, Cranston, and Snell, 1964a). It has also been claimed that lesions in the region of the tuber cinereum may be associated with intermittent pyrexia, and the hyperpyrexia of head injury and subarachnoid haemorrhage are well recognized but poorly understood. In hyperthermia associated with central nervous system lesions thermoregulatory responses have not, as yet, been adequately assessed and the mechanism by which central hyperthermia occurs in man remains incompletely understood. We wish to record, therefore, autonomic function studies on a child with cerebral gigantism and persistent unexplained fever.

\section{CASE HISTORY}

The patient is 19 months old and is a severely mentally retarded girl. She was born to a primiparous 23-year-old mother. The father is 36 years old and has five other children by a previous marriage. There is no family history of mental retardation or other neurological disease.

The pregnancy was normal and the child was delivered at term. The labour lasted six hours. Presentation was vertex and low forceps were used. Birth weight was $3.9 \mathrm{~kg}$. Hypotonia was noted at birth. In the first three days of life the rectal temperature could not be maintained above $36^{\circ} \mathrm{C}$ without a warmer. On the fifth day of life, the infant appeared jaundiced and the indirect bilirubin was $21 \mathrm{mg} \%$. The Coombs test was negative, reticulocyte count $5 \%$, nucleated red blood cells less than five, blood culture negative, blood serology negative, urine negative for cytomegalic inclusion bodies, blood type B, $\mathrm{Rh}$ positive. The mother's blood was type $A, R h$ positive. The jaundice subsided and the infant was discharged two days later. She was not febrile during this hospitalization.

At 2 weeks of age the patient developed a stuffy nose and a temperature of $40^{\circ} \mathrm{C}$ rectally. Dimethylchlortetra- cycline was given. Because of persistent fever a urine analysis was performed one week later. The urine contained 20 white cells per high power field. Extensive urological examination including intravenous pyelogram, cyctoscopy, and many urine analyses and cultures failed to verify any renal infection or other abnormalities. The temperature elevation has persisted ever since, varying between $37.8^{\circ} \mathrm{C}$ and $40^{\circ} \mathrm{C}$ with no discernible diurnal cycle. Despite repeated extensive investigation, no source of infection has ever been found.

Although she was able to hold her head up at 2 months of age, she has never rolled over or showed other signs of more advanced motor development. There is no speech. At about 9 months of age, her appetite increased markedly. By 12 months of age she weighed $13.6 \mathrm{~kg}$ and was $83.8 \mathrm{~cm}$ long (both above 97th percentile on the Children's Medical Center, Boston Anthropometric Chart).

At the age of 19 months she weighed $16.3 \mathrm{~kg}$ and was $93.9 \mathrm{~cm}$ long (Fig. 1). No abnormalities were noted on examination of the heart and there were no abdominal masses. The skin was warm, smooth, and dry except for some slight moisture in the folds of the neck and about the scalp hair line. Head circumference was $18 \frac{1}{2}$ in. She was irritable when handled. The skull was dolichocephalic with frontal bossing. The palpebral fissures had an antimongoloid slant. There was a high arched palate. Constant wandering eye movements were present and there was no evidence of meaningful vision. The pupils were equal and reactive and funduscopic examination showed normal discs and retinae. Loud noise produced generalized myoclonic jerking. Hypotonia was marked. The extremities moved equally and withdrawal occurred from painful stimulation. The deep tendon reflexes were present and symmetrical. The toe sign was extensor bilaterally.

The results of laboratory examinations were as follows: haemoglobin, $11.7 \mathrm{~g} \%$; haematocrit $35 \%$; white blood count 14,100 , band forms $1 \%$, lymphocytes $73 \%$, segmented polymorphs $22 \%$; monocytes $2 \%$, eosinophils $2 \%$; sodium 149 m-equiv/l., potassium $5 \mathrm{~m}$-equiv/l., chloride 116 m-equiv/l., $\mathrm{CO}_{2} 17.7 \mathrm{~m}$-equiv/l., calcium $5.2 \mathrm{~m}$-equiv/l., phosphorus $2 \mathrm{~m}$-equiv/1.; creatinine $0.4 \mathrm{mg}$ $\%$; albumin $3.97 \mathrm{~g} \mathrm{\%}, \alpha$-l-globulin $0.18 \mathrm{~g} \%, \alpha-2-$ globulin $0.67 \mathrm{~g} \%, \beta$ globulin $0.85 \mathrm{~g} \%, \gamma$ globulin $0.43 \mathrm{~g}$ $\%$.

Urine analysis yellow, clear, specific gravity 1.009 , no protein, sugar or acetone, haematest negative, 2 to 8 white blood cells/hpf; urine nitroprusside negative. 


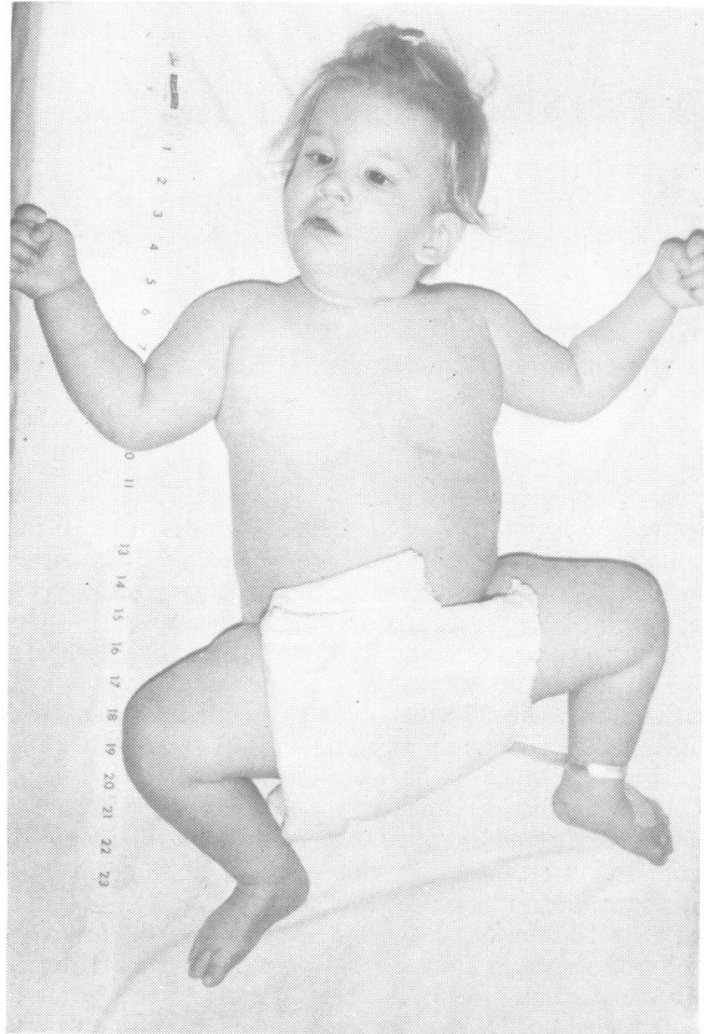

FIG. 1. The patient aged 19 months.

Blood pressure (systolic) was $70 \mathrm{~mm} \mathrm{Hg}$ supine and $55 \mathrm{~mm}$ $\mathrm{Hg}$ after being supported upright for five minutes.

Cerebrospinal fluid was clear, 60 red blood cells, sugar $54 \mathrm{mg} \%$. Aminoacid chromatography of blood and urine was normal. Electroencephalogram showed excessive slow waves especially on the right side. Skull and chest radiographs were normal, as was bone age. Lumbar $\mathbb{Q}$ pneumoencephalogram showed cortical atrophy with marked dilatation of suprasellar cisterns (Figs. 2, 3, 4). There was a normal electrocardiogram; FSH was less than 6 mouse units (normal), 17 ketosteroids $1.8 \mathrm{mg} / 24 \mathrm{hr} 0$ (normal), ketogenic steroids $1.5 \mathrm{mg} / 24 \mathrm{hr}$ (normal). Conduction velocities were normal for age in the right $\stackrel{\rho}{?}$ posterior tibial, peroneal, and ulnar nerves, normal muscle potentials. Skin biopsy showed normal hair follicles, erectores pilorum, sebaceous glands, sweat glands, and peripheral nerves. Buccal smear showed female sex chromatin pattern; intermediate strength PPD was $\frac{\overrightarrow{0}}{0}$ negative.

SPECIAL INVESTIGATIONS The investigations carried out in this patient are summarized in Table I.

Vasomotor changes in response to trunk heating Vasomotor changes were measured with heat flow disks (Hatfield, 1950) in the right thumb and big toe (Fig. 5) $\overrightarrow{0}$ during radiant heating of the trunk. Heat elimination remained unchanged, This indicated the absence of $\vec{\omega}$ normal reflex vasodilatation in these sites.

Body cooling The patient was cooled by means of a cooling blanket for $2 \frac{1}{2}$ hours. The temperature in the external auditory meatus, which is a good approximation of $N$ central temperature (Cooper, Cranston, and Snell, 1964b iv dropped from $39.5^{\circ} \mathrm{C}$ to $33.4^{\circ} \mathrm{C}$. No shivering waे $\vec{N}$ observed. Ten minutes after removal of the cooling $\omega$ blanket, some trembling of lips occurred while the teng perature in the external auditory meatus was $33 \cdot 6^{\circ} \mathrm{C}$. No further movements resembling shivering were observe and the temperature returned to the usual level.

Sweating The temperature in the external auditor meatus was raised from $40 \cdot 25^{\circ} \mathrm{C}$ to $41 \cdot 25^{\circ} \mathrm{C}$ using a hea cradle. No sweating was seen nor observed after quinizarin powder was applied (Guttmann, 1940) to the face and anterior aspects of the limbs and trunk.

Pilocarpine iontophoresis produced $218.5 \mathrm{mg}$ of sweat containing $67.5 \mathrm{mg} \%$ sodium, and $19.5 \mathrm{mg} \%$ potassium.

This indicated that centrally induced sweating was

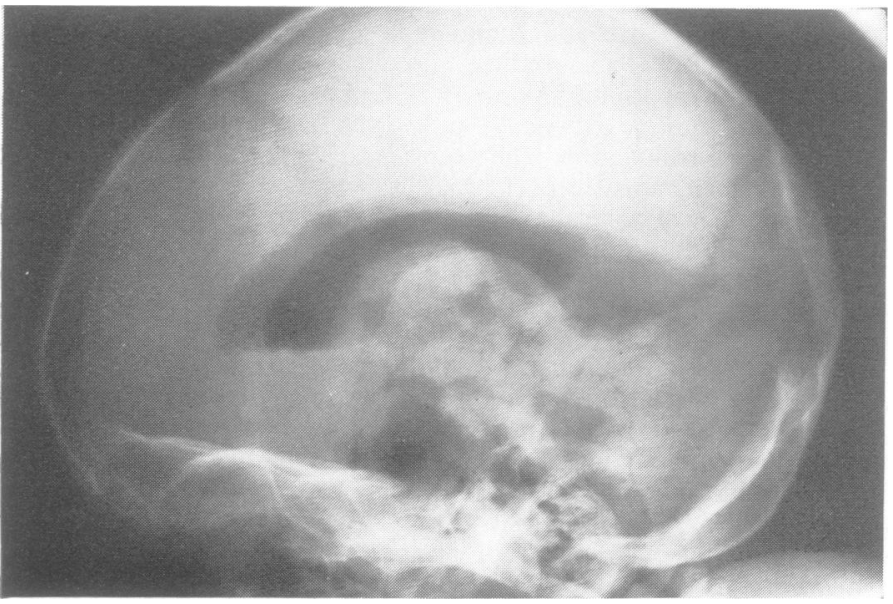

FIG. 2. Lateral view of lumbar pneumoencephalogram showing dilated interpeduncular cistern. 


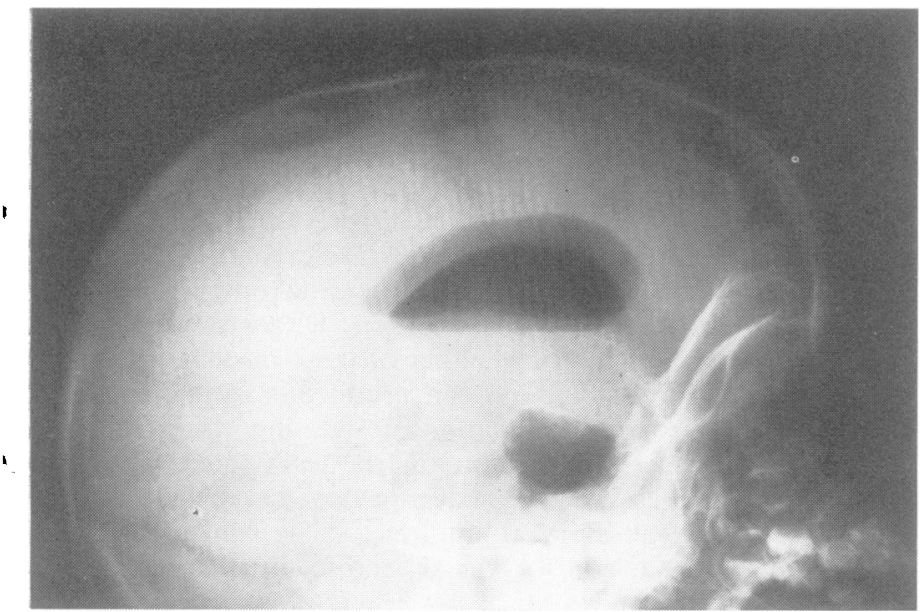

FIG. 3. Similar view of lumbar pneumoencephalogram showing slightly dilated ventricles and excessive air over the hemisphere surface in the frontal region. defective but peripheral sweat gland activity could be normally induced by direct stimulation.

Local skin responses The intradermal injection of methacholine chloride produced normal pilo-erection demonstrating that post-ganglionic pilomotor fibres were normal. Intradermal injection of $0.1 \mathrm{ml} .1: 1000$ histamine induced a normal triple response of Lewis showing normal function of peripheral sensory fibres.

Vagus nerves There was no increase in pulse rate after $0.15 \mathrm{mg}$ atropine intravenously. Ocular pressure or carotid sinus massage did not decrease the heart rate. These results were consistent with absent vagus activity at rest and on stimulation. An insulin test meal was performed by giving $0 \cdot 15 \mathrm{u}$. soluble insulin intravenously. This did not lead to an increase in gastric acidity indicating absent vagal activity in response to the effect of hypoglycaemia on the brain (Hollander, 1946; Bachrach, 1953).

Pupillary responses There was a normal reaction directly and consensually to light in either pupil, and the instillation of $2.5 \%$ methacholine chloride was without effect, indicating that there was no denervation supersensitivity of the para-sympathetic pupillary constrictor fibres (Smith and Dancis, 1963).

\section{DISCUSSION}

The patient described in this report suffers from cerebral gigantism and conforms to the clinical description of this condition originally given by Sotos, Dodge, Muirhead, Crawford, and Talbot (1964). The main features of this disease are an increase in height and weight with accelerated skeletal maturation and mental retardation. Numerous cases have been reported (Stephenson, Mellinger, and Manson, 1968) and their clinical features reviewed (Milunsky, Cowie, and Donoghue, 1967). Children with cerebral gigantism are well proportioned, though hands and feet are large and the subcutaneous tissues are thickened. The forehead is usually prominent and the eyes have an anti-mongoloid slant. A high arched palate is often found. The radiographic findings include an enlarged skull and ventricular system, but a number of other radiographic features, though less frequently found, accompany this disorder. These include cavum septum pellucidum and velum interpositum, an abnormal appearance of the dorsum sellae, and increased interorbital distance with anterior fontanelle bones (Poznanski and Stephenson, 1967). Many of these features, including mental retardation and dilated cerebral ventricles, were found in our patient.

The clinical features of this condition suggest increased pituitary function, but extensive endocrinological studies have so far not substantiated this. Stephenson et al. (1968) showed that glucose tolerance was normal as was the free fatty acid response after administration of growth hormone, and the levels of this hormone in the plasma were also normal. Although the urinary 17 ketosteroid excretion was increased for chronological age, the levels were in keeping with the physiological age of the patients and the responses to dexamethasone suppression and metapyrone administration were normal in their patients. Nevertheless, the condition has been attributed to a congenital disturbance in central nervous system function which is manifested by mental retardation and an altered hypothalamic control of the anterior pituitary.

The results of autonomic function tests in our patient clearly point to a central failure of temperature control. The patient was continuously febrile but not sweaty in a warm environment, but she could artificially be cooled without shivering. Thermoregulatory sweating was absent when the 


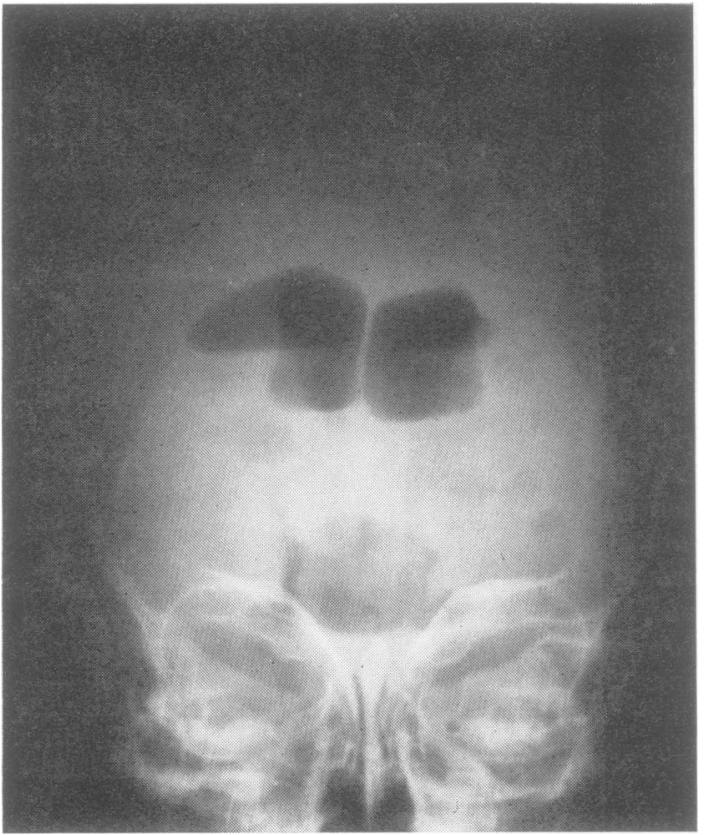

FIG. 4. $P-A$ view of lumbar pneumoencephalogram showing the dilated interpeduncular cistern and ventricles. patient was heated, but sweating could be initiated by pilocarpine iontophoresis and histologically the sweat glands were normal.

It is not entirely clear whether thermoregulatory sweating is due to a rise in blood temperature which 0 activates central structures responsible for thermo- $\tau$ regulation, or whether a peripheral heat sensitive receptor reflexly activates these central structures, which in turn initiate post-ganglionic sympathetic activity and sweat secretion. Under certain experimental conditions either of these mechanisms alone or in combination can produce sweating. In a hot environment, initiation of sweating varies with the thermal adaptation of the individual. In non- $\frac{\sigma^{3}}{}$ adapted subjects an abrupt rise in ambient tempera- $\vec{\nabla}$ ture causes sweating after a delay, which correlates with a rise in rectal and tympanic membrane $\infty$ temperatures but is not related to skin temperature. $\overrightarrow{0}$ Adapted subjects under similar conditions, however, $\vec{\overrightarrow{ }}$ show an immediate onset of sweating which is re- $\vec{\omega}$ lated to the rise in skin temperature, and a further increase in sweating occurs coinciding with the rise in rectal temperature (Colin and Houdas, 1965). In young children between 1 and 7 years of age, there $N$ moregulatory sweating is normally more pre nounced on the trunk and chest than in adults und $\mathrm{s}$ similar conditions (Lipton, Steinschneider, and 을

TABLE I

SPECIAL INVESTIGATIONS

\begin{tabular}{lll}
\hline Tests & Response & Conclusion
\end{tabular}

Reflex vasodilatation in digit pulps No vasodilatation

Body cooling (external auditory meatus temperature $39 \cdot 5^{\circ}-33 \cdot 4^{\circ} \mathrm{C}$ )

Body heating (external auditory meatus temperature $40 \cdot 25^{\circ}-41 \cdot 25^{\circ} \mathrm{C}$ )

Pilocarpine iontophoresis

Skin biopsy

Intradermal methacholine chloride ( $2.5 \mathrm{mg})$

Intradermal histamine $1: 1000(0 \cdot 1 \mathrm{ml}$.)

Intravenous atropine $(0 \cdot 15 \mathrm{mg})$

Ocular pressure and carotid sinus massage

Insulin test meal (0.15 u. intravenously)

Instillation of $2.5 \%$ methacholine chloride into conjunctival sac

Motor nerve conduction velocities
No shivering

No sweating

Profuse sweating

Histologically normal sweat glands

Piloerection

Triple response of Lewis

No increase in heart rate

No decrease in heart rate

No increase in gastric acidity

No pupillary constriction

Right ulnar $37 \mathrm{~m} / \mathrm{sec}$

Right peroneal $27.9 \mathrm{~m} / \mathrm{sec}$

Right posterior tibial $30.4 \mathrm{~m} / \mathrm{sec}$
Consistent with interruption of reflex arc due to disfunction of thermoregulatory structures rostral to brain-stem

Consistent with failure of central thermoregulation

Consistent with failure of central thermoregulation

Sweat glands functionally intact

Sweat glands morphologically intact

Normal post-ganglionic pilomotor fibres

Normal function of peripheral pain fibres

Impaired vagus activity at rest

Impaired vagus activity on stimulation

Impaired vagus activity

No parasympathetic denervation supersensitivity

Lower limit of normal for age 


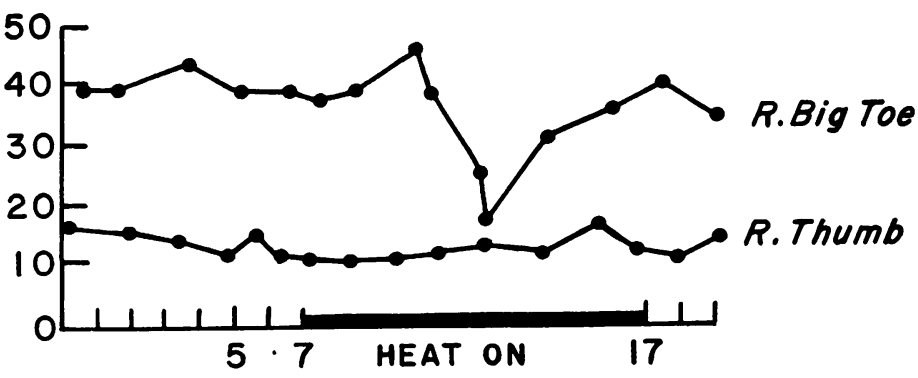

FIG. 5. Heat elimination from digits during radiant heating of the trunk.

MINUTES

Richmond, 1965), so that the patient's age was not a factor in the disturbance of thermoregulatory sweating. Either or both mechanisms which normally initiate thermoregulatory sweating were defective in our patient and this defect was probably related to dysfunction of central structures concerned with thermoregulation because the peripheral sweat mechanism was shown to be intact.

Changes in hand blood flow are largely the result of alterations in the amount of blood flowing through the skin and this is entirely controlled by sympathetic vasoconstrictor nerves. Vasodilatation is the result of an inhibition of constrictor tone, no vasodilator fibres being involved (Roddie, Shepherd, and Whelan, 1957). Reflex vasodilatation in hand vessels can be elicited by heating the skin elsewhere (Kerslake and Cooper, 1950). This reflex is dependent on neural afferents from the heated area, central structures situated rostral to the brain-stem, and sympathetic efferents to blood vessels. Reflex vasodilatation is absent in sympathectomized hands and also in patients with syringomyelia and high brain-stem lesions-where presumably the afferent limb of this reflex is interrupted by the lesion (Appenzeller and Schnieden, 1963). Fever does not interfere with reflex vasodilatation once the temperature has reached a plateau (Cooper et al., 1964a). In our patient, no clinical evidence of brain-stem lesions was found and such lesions have not previously been reported in cerebral gigantism. There was no evidence of post-ganglionic sympathetic denervation of the hand or foot, but evidence for intact post-ganglionic fibres was obtained because of normal pilo-erection. Moreover, motor nerve conduction velocities in upper and lower limbs were also normal. On the afferent side, the skin remained normally sensitive to pain and the triple response of Lewis was also normal, suggesting that afferent pain fibres were intact. By exclusion, we postulate that the failure to elicit reflex vasodilatation in the hand or foot in response to heating of the chest-like the lack of thermoregulatory sweating and shivering-was due to dysfunction of structures rostral to the brainstem, probably situated in the hypothalamus. There was additional evidence for central disturbances of autonomic control. Thus the tests of vagal function were all impaired but pupillary responses after methacholine chloride were normal, indicating normal parasympathetic post-ganglionic innervation. In addition, the pneumoencephalogram showed a large interpeduncular cistern consistent with atrophy in the region of the hypothalamus.

Autonomic failure in the elderly is sometimes accompanied by hypothermia rather than fever. In our patient such a failure was associated with persistent fever but she was unable to maintain her temperature in the perinatal period or when artificially cooled. A likely explanation for this apparent discrepancy is a combination of a high metabolic rate which is normal in children, together with the usually warm environment to which the patient was exposed at home.

A wide range of intellectual deficits in cerebral gigantism is usually found (Stephenson et al., 1968). Hyperthermia may lead to loss of neurones but the contribution of long-lasting fever to the severe mental retardation in our patient remains conjectural. While the aetiology of cerebral gigantism is unknown, the assumption that it might be related to hypothalamic deficits is strengthened by what, for the present, must remain a fortuitous association of this condition with autonomic failure. 


\section{SUMMARY}

A case of cerebral gigantism with persistent fever is described. Tests of autonomic function and neurological and radiographic findings suggested that a lesion in the hypothalamus might have caused the autonomic deficit. This apparently fortuitous association strengthens the suggestion previously made that cerebral gigantism is related to hypothalamic malfunction.

\section{REFERENCES}

Appenzeller, O., and Schnieden, H. (1963). Neurogenic pathways concerned in reflex vasodilatation in the hand with especial reference to stimuli affecting the afferent pathway. Clin. Sci., 25, 413-421.

Bachrach, W. H. (1953). Action of insulin hypoglycemia on motor and secretory functions of the digestive tract. Physiol. Rev., 33, 566-592.

Colin, J., and Houdas, Y. (1965). Initiation of sweating in man after abrupt rise in environmental temperature. J. appl. Physiol., 20, 984-990.

Cooper, K. E., Cranston, W. I., and Snell, E. S. (1964a). Temperature regulation during fever in man. Clin. Sci., 27, 345-356.

,--1 (1964b). Temperature in the external auditory meatus as an index of central temperature changes. J. appl. Physiol., 19,1032-1035.

Guttman, L. (1940). Topographic studies of disturbances of sweat secretion after complete lesions of peripheral nerves. J. Neurol. Psychiat., 3, 197-210.

Hatfield, H. S. (1950). A heat-flow meter. J. Physiol. (Lond.), 111, $10 \mathrm{P}-11 \mathrm{P}$.

Hollander, F. (1946). The insulin test for the presence of intact nerve fibers after vagal operations for peptic ulcer. Gastroenterology, 7, 607-614.

Kerslake, D. McK., and Cooper, K. E. (1950). Vasodilatation in the hand in response to heating the skin elsewhere. Clin. Sci., 9, 31-47.
Lipton, E. L., Steinschneider, A., and Richmond, J. B. (1965). The autonomic nervous system in early life. New Engl. J. Med., T 273, 147-153.

Milunsky, A., Cowie, V. A., and Donoghue, E. C. (1967). Cerebral gigantism in childhood. A report of two cases and a review of the literature. Pediatrics, 40, 395-402.

Poznanski, A. K., and Stephenson, J. M. (1967). Radiographic findings in hypothalamic acceleration of growth associated with cerebral atrophy and mental retardation (cerebral gigantism). Radiology, 88, 446-456.

Roddie, I. C., Shepherd, J. T., and Whelan, R. F. (1957). The vasomotor nerve supply to the skin and muscle of the human forearm. Clin. Sci., 16, 67-74.

Smith, A. A., and Dancis, J. (1963). Physiologic studies in familial dysautonomia. J. Pediat., 63, 838-840.

Sotos, J. F., Dodge, P. R., Muirhead, D., Crawford, J. D., and Talbot, N. B. (1964). Cerebral gigantism in childhood. A syndrome of excessively rapid growth with acromegalic features and a non- $\mathcal{S}$ progressive neurologic disorder. New Engl. J. Med., 271, 109-116.

Stephenson, J. N., Mellinger, R. C., and Manson, G. (1968). Cerebra gigantism. Pediatrics, 41, 130-138.

\section{ADDENDUM}

Dr. Hortense M. Gandy, of the Cornell Medica Center, New York, has kindly estimated the etiog $\tilde{\omega}$ cholanolone levels in the serum of the above patien $\mathbb{8}$ 을 The concentration was $0.03 \mu \mathrm{g} \%$ (normal rango0.03 to $0.09 \mu \mathrm{g} \%$ ).

Etiocholanolone is a pyrogenic steroid and elev ated levels in the serum may correlate with otherwise. unexplained fever and have been found in a variet of conditions including anoxic anencephaly. The normal serum concentration in our patient is consistent with the explanations offered in the discussion. 